\title{
Efficacy of peginterferon $\alpha$-2a and predictors of response in HBeAg-negative, genotype D-naive patients
}

\author{
Hamad I. Al-Ashgar • Mohammed Q. Khan • Abdulrahman Aljumah • \\ Faisal M. Sanai - Ayman A. Abdo • Mutasim M. Dafalla - Mosa A. Fagih • \\ Khalid I. Bzeizi
}

Received: 12 February 2011/ Accepted: 10 November 2011/Published online: 25 November 2011

(C) Asian Pacific Association for the Study of the Liver 2011

\begin{abstract}
Background Peginterferon (PEG-IFN) $\alpha-2 \mathrm{a}$ has been shown to induce a sustained virologic response (SVR) in 20-30\% of "hepatitis B e antigen ( $\mathrm{HBeAg}$ )"-negative patients.

Aim To determine the safety and efficacy of PEG-IFN $\alpha$-2a in HBeAg-negative, genotype D-naive patients and to analyze the predictors of response.

Methods This prospective, multicenter, open-label, nonrandomized trial was conducted at four hospitals. A total of 35 consecutive HBeAg-negative naive genotype D patients received PEG-IFN $\alpha$-2a for 48 weeks.

Results Based on a cutoff of hepatitis B virus (HBV) DNA $<400$ copies $\mathrm{ml}^{-1}$, an early virologic response (EVR) at week 12, end of treatment virologic response (ETVR) at week 48, and SVR at week 72 were achieved by $3(9 \%), 9$ (26\%), and 8 patients (23\%), respectively. The EVR rate improved to $43 \%$, ETVR to $49 \%$, and SVR to $57 \%$, when a HBV DNA cutoff level of $<20,000$ copies $\mathrm{ml}^{-1}$ was used. Pretreatment HBsAg level was not a predictor for SVR on
\end{abstract}

H. I. Al-Ashgar · M. Q. Khan $(\bowtie) \cdot$ M. A. Fagih Section of Gastroenterology, Department of Medicine (MBC-46), King Faisal Specialist Hospital and Research Center, P.O. Box 3354, Riyadh 11211, Saudi Arabia e-mail: mohamedkhan@kfshrc.edu.sa

\section{A. Aljumah · M. M. Dafalla}

King Abdulaziz Medical City and King Saud bin Abdulaziz University for Health Sciences, Riyadh, Saudi Arabia

F. M. Sanai · K. I. Bzeizi

Armed Force Hospital, Riyadh, Saudi Arabia

A. A. Abdo

King Saud University Liver Disease Research Center, Riyadh, Saudi Arabia univariate analysis, but correlated with decline in $\mathrm{HBV}$ DNA levels at weeks 48 and 72. On multivariate logistic regression analysis, low body weight, high alanine aminotransferase (ALT), low HBV DNA, and low triglyceride levels were identified as baseline predictors of SVR.

Conclusion HBeAg-negative genotype D-naive patients treated with PEG-IFN $\alpha-2 \mathrm{a}$ achieved SVR in 23 (HBV $<400$ copies $\mathrm{ml}^{-1}$ ) and $57 \%\left(\mathrm{HBV}<20,000\right.$ copies $\mathrm{ml}^{-1}$ ) of patients, a better response than previously reported that might be related to the absence of drug resistance in these naive patients. Pretreatment predictors of SVR were low body weight, high ALT, low HBV DNA, and low triglycerides.

Keywords HBeAg-negative - Genotype D . Peginterferon

\section{Introduction}

Hepatitis B infection is a major global health problem responsible for more than one million deaths annually due to cirrhosis and hepatocellular carcinoma (HCC) [1]. Among chronic hepatitis B (CHB) patients in Saudi Arabia, $>70 \%$ are "hepatitis B e antigen ( $\mathrm{HBeAg}$ )"-negative and the most common genotype is genotype D (81.2\%) [2]. Asian patients are less likely to experience $\mathrm{HBeAg}$ seroconversion than Caucasians after receiving interferon as reported in earlier studies [3]. Asians usually acquire hepatitis $B$ virus (HBV) infection in infancy and have a long immune-tolerance phase, which may render immunomodulation with interferon therapy less effective [4]. Treatment with currently available oral nucleoside/nucleotide analogs may be associated with development of drug resistance and relapse after discontinuation of therapy. 
Thus, more efficacious therapies are needed that can suppress HBV for a longer duration after discontinuation of antiviral therapy without the development of drug-induced viral mutation. Peginterferon (PEG-IFN) $\alpha$-2a has both antiviral and immunomodulatory effects that may be associated with long-term viral suppression [5]. Previous studies were conducted where exclusion criteria included antiviral therapy only within the preceding 6 months $[6,7]$, where some of the patients received conventional interferon or nucleotide/nucleoside analogs earlier than 6 months before treatment with PEG-IFN, and the higher probability of developing drug resistance could have altered the response of PEG-IFN $\alpha-2 \mathrm{a}$ in trials. It is, therefore, relevant to study the sustained virologic response (SVR) to PEG-IFN in naive Middle Eastern HBeAg-negative genotype D patients. Suppression of serum HBV DNA to $<400$ copies $\mathrm{ml}^{-1} 6$ months after 48 weeks of therapy is a good indicator of 3-year posttreatment response [7]. In the present study, SVR was defined as suppression of HBV DNA level $<400$ copies $\mathrm{ml}^{-1}$ with normalization of alanine aminotransferase (ALT) 6 months after completion of 48 weeks of therapy. We also assessed the suppression of $\mathrm{HBV}$ DNA $<20,000$ copies $\mathrm{ml}^{-1}$ as another coprimary efficacy parameter [8] and HBsAg levels at the end of treatment and 6 months after completion of treatment. Predictors of response are useful to provide the appropriate antiviral therapy to the most suitable patients, in order to achieve the best response and improve the clinical outcome of CHB patients [9]. HBV genotype and HBsAg levels have recently emerged as predictive factors of response to therapy in $\mathrm{HBeAg}$-negative $\mathrm{CHB}$, in addition to previously established factors of elevated serum ALT, lower HBV DNA, and higher necroinflammatory activity. We aimed to study the safety and efficacy of 48 weeks of PEG-IFN $\alpha$-2a therapy in HBeAg-negative genotype $\mathrm{D}$ treatment-naive patients, and correlate the decline in HBV DNA levels with quantitative changes in serum HBsAg levels at the baseline, at the end of treatment, and at the end of follow-up period. We also aimed to identify predictors of response to therapy.

\section{Patients and methods}

Patients

This study was conducted between January 2007 and November 2009 at four tertiary referral hospitals (King Faisal Specialist Hospital and Research Center, Riyadh Military Hospital, King Saud University Liver Disease Research Center, and King Abdulaziz Medical City) in Riyadh, Saudi Arabia. The study was conducted in accordance with good clinical practice and the Declaration of
Helsinki, and was approved by the research committees and institutional review boards of each participating center. HBsAg-positive, genotype D-infected naive patients aged 18-70 years were included if they had been negative for $\mathrm{HBeAg}$ and positive for anti-HBe antibody for $\geq 6$ months, had a HBV DNA level of $>100,000$ copies $\mathrm{ml}^{-1}$, had a serum ALT level greater than the upper limit of normal $\left(\mathrm{ULN}=43 \mathrm{U}^{-1}\right)$ but $<10 \times \mathrm{ULN}$, and a liver biopsy obtained within the previous 12 months demonstrating at least $\geq \mathrm{F} 1$ and/or $\geq \mathrm{A} 1$ (METAVIR classification). Exclusion criteria included decompensated liver disease (defined as presence or prior history of ascites, variceal bleeding, encephalopathy, or international normalized ratio (INR) $\geq 1.3$ ), a coexisting major medical or psychiatric illness, a neutrophil count of $<1,500$ per cubic millimeter, a platelet count of $<90,000$ per cubic millimeter, a serum creatinine level $>1.5 \times$ ULN, a history of alcohol or drug abuse, coinfection with hepatitis $\mathrm{C}$, hepatitis $\mathrm{D}$, or human immunodeficiency virus, any other liver and autoimmune diseases, and general contraindication to interferon therapy.

Study design

This was an independent, investigator-initiated, prospective, multicenter, open-label, nonrandomized trial, designed to assess the efficacy of PEG-IFN $\alpha$-2a in treatment-naive (no prior exposure to nucleoside/nucleotide analogs or interferon) HBeAg-negative patients. Only patients without baseline drug resistance mutations were included, and written informed consent was obtained from all patients. The coprimary endpoints of the study were ALT normalization and a HBV DNA level of $<400$ copies $\mathrm{ml}^{-1}$ measured at 24 weeks posttreatment (week 72). To predict SVR, all the measurements for univariate and multivariate analysis were performed on HBV DNA level of $<400$ copies $\mathrm{ml}^{-1}$. All patients received PEG-IFN $\alpha$-2a $180 \mu \mathrm{g}$ once weekly for 48 weeks and the dose of PEG-IFN $\alpha$-2a was reduced to $135 \mu \mathrm{g}$ weekly if neutrophil count dropped to $<0.75 \times 10^{9} 1^{-1}$, whereas it was withdrawn in patients where count dropped to $<0.50 \times 10^{9} 1^{-1}$. The same dose reductions were applied when platelets were $<50,000 \mathrm{~mm}^{-3}$ with PEG-IFN $\alpha$-2a being discontinued when counts reduced below 25,000 $\mathrm{mm}^{-3}$. Administration of granulocyte-colony stimulating factor (G-CSF) was allowed. In the present analyses, early virological response (EVR), end of treatment virological response (ETVR), and SVR were defined as HBV DNA $<400$ copies $\mathrm{ml}^{-1}$ at weeks 12,48 , and 72 , respectively, with normalization of serum ALT. Patients with HBV DNA $>400$ copies $\mathrm{ml}^{-1}$ at 24 weeks posttreatment were considered as nonresponders (i.e., treatment failures). Posttreatment virologic relapse was defined as HBV DNA level of

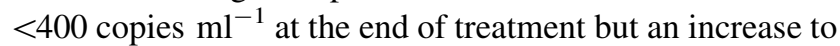
$>400$ copies $\mathrm{ml}^{-1}$ at 24 weeks posttreatment. Suppression 
of HBV viral load to $<20,000$ copies $\mathrm{ml}^{-1}$ at weeks 12,48 , and 72 was also calculated.

\section{Measurements}

Serum samples were collected from each patient at entry and stored at $-70^{\circ} \mathrm{C}$ until further tests (Table 1) were performed. During therapy and posttreatment follow-up evaluation for 6 months, the patients were monitored monthly by routine physical examination as well as biochemical and hematological assessments to analyze the predictor of response. HBV DNA was measured by the Quantiplex ${ }^{\mathrm{TM}}$ HBV DNA assay (Chiron diagnostics, USA) at $0,12,24,36$, and 48 weeks during treatment and 6, 8, and 24 weeks after discontinuation of treatment. All results $<400$ copies $\mathrm{ml}^{-1}$ were confirmed by the Abbott RealTime HBV assay using the m2000rt platform (Abbott Diagnostics, USA) for lower limit detection. In the initial period, serum HBV DNA was expressed in copies per milliliter (copies $\mathrm{ml}^{-1}$ ), and at the later stages of the study it was expressed in international units per milliliter (IU ml ${ }^{-1}$ ). After the completion of the study, all $\mathrm{HBV}$ DNA measurements were converted into copies $\mathrm{ml}^{-1}$ ( $1 \mathrm{IU} \mathrm{ml} \mathrm{m}^{-1}=3.41$ copies $\mathrm{ml}^{-1}$ ). Serum HBsAg levels were measured at baseline, end of treatment (at 48 weeks), and 6 months after discontinuation of treatment (72 weeks). HBV genotyping with HBV mutation in the precore and core promoter regions of the viral genomes were performed at baseline using the Inno-LiPa HBV DR v2 (Innogenetics, Ghent, Belgium) to confirm that there were no pretreatment genetic mutations. Serum HBsAg was quantified by using the Abbott Architect HBsAg QT two-step assay. The sensitivity of the assay ranged from 0.05 to $250 \mathrm{IU} \mathrm{ml}^{-1}$. Samples with HBsAg titers beyond the upper range were diluted with phosphate buffered saline (PBS) into 1:10, 1:1,000, and 1:10,000 before further analysis. All analyses of HBV DNA levels, HBV genotype, and serum HBsAg levels were performed centrally at King Faisal Specialist Hospital and Research Center (KFSHRC) and the histopathological examination was read by a single pathologist (blinded for the outcome).

\section{Statistical analysis}

Quantitative variables were expressed as the mean plus or minus standard deviation or the median with interquartile range (IQR) and categorical variables as absolute and relative frequencies. Comparisons between groups of quantitative and qualitative variables were performed using the Mann-Whitney test or Student's $t$ test and the Fisher's exact test, respectively. Age, sex, weight, HBV DNA, ALT, HBsAg levels, hemoglobin, leukocyte count, platelets, bilirubin, gamma-glutamyl transpeptidase (GGT), alkaline phosphatase, $\alpha$-fetoprotein, albumin, cholesterol, triglycerides, and histopathology variables were analyzed as predictors under univariate analysis. Multivariate

Table 1 Basic characteristic between responders and nonresponders

\begin{tabular}{|c|c|c|c|c|}
\hline Characteristics & $\begin{array}{l}\text { All patients } \\
(n=35)\end{array}$ & $\begin{array}{l}\text { Responders } \\
(n=20)\end{array}$ & $\begin{array}{l}\text { Nonresponders } \\
(n=15)\end{array}$ & $p$ value \\
\hline Age (years) & $38.7 \pm 11.5$ & $36.5 \pm 10.5$ & $41.8 \pm 12.5$ & 0.214 \\
\hline Sex $($ male $\%)$ & $33(94)$ & $19(57.7)$ & $14(42.4)$ & 1.000 \\
\hline Weight, median (IQR) & $77.0(66.6-81.0)$ & $77.2(66.05-80.75)$ & $77.0(72.50-86.00)$ & 0.043 \\
\hline Serum ALT $\left(\mathrm{IU} 1^{-1}\right)$ & $80(59-143)$ & $94(67-195)$ & $71(43-84)$ & 0.034 \\
\hline Serum HBV DNA (log copies $\mathrm{ml}^{-1}$ ) & $6.6(5.7-7.8)$ & $5.8(5.5-6.8)$ & $7.8(6.6-7.8)$ & 0.004 \\
\hline Serum HbsAg $\left(\log \mathrm{IU} \mathrm{ml}^{-1}\right)$ & $4.0(3.7-4.4)$ & $4.0(3.7-4.6)$ & $3.9(3.7-4.3)$ & 0.882 \\
\hline Hemoglobin $\left(\mathrm{gm} \mathrm{l}^{-1}\right)$ & $154(144-163)$ & $154(142-167)$ & $153(144-157)$ & 0.221 \\
\hline Leucocyte count $\left(10^{9} 1^{-1}\right)$ & $5.6(4.8-6.9)$ & $6.0(5.0-7.3)$ & $5.2(4.2-5.8)$ & 0.064 \\
\hline Platelets $\left(10^{9} 1^{-1}\right)$ & $225(177-266)$ & $220(177-264)$ & $243(177-301)$ & 0.379 \\
\hline Bilirubin $\left(\mu \mathrm{mol} \mathrm{1} 1^{-1}\right)$ & $11(9-14)$ & $10(9-14)$ & $11(7-18)$ & 0.908 \\
\hline Alkaline phosphatase $\left(\mathrm{U}^{-1}\right)$ & $87(76-121)$ & $90(70-134)$ & $86(80-120)$ & 0.888 \\
\hline GGT (IU $\left.1^{-1}\right)$ & $51(32-78)$ & $46(32-78)$ & $53(33-79)$ & 0.939 \\
\hline$\alpha$-Fetoprotein $\left(\mu \mathrm{g}^{-1}\right)$ & $4.3(3.1-6.2)$ & $4.0(2.7-5.4)$ & $5.6(4.1-8.8)$ & 0.093 \\
\hline Albumin $\left(\mathrm{g}^{-1}\right)$ & $45(40-46)$ & $44(41-46)$ & $45(40-48)$ & 0.749 \\
\hline Cholesterol $\left(\mathrm{mmol} \mathrm{1}^{-1}\right)$ & $4.3(3.8-5.0)$ & $4.3(3.8-4.9)$ & $4.3(3.8-5.3)$ & 0.674 \\
\hline Triglycerides $\left(\mathrm{mmol} \mathrm{1}^{-1}\right)$ & $1.29(0.79-1.85)$ & $0.80(0.645-1.283)$ & $1.85(1.30-2.10)$ & 0.002 \\
\hline $\begin{array}{l}\text { Liver biopsy: grade A1 and A2 (METAVIR classification) } \\
(\%)\end{array}$ & $33(94)$ & $17(51.5)$ & $16(48.5)$ & 0.489 \\
\hline Liver biopsy: stage F1 and F2 (METAVIR classification) (\%) & $29(83)$ & $15(51.7)$ & $14(48.2)$ & 0.666 \\
\hline
\end{tabular}

Median (IQR) 
analysis using stepwise logistic regression was performed to identify independent factors associated with the response. Correlation between serum HBsAg and $\mathrm{HBV}$ DNA levels was performed using Spearman rank correlation. All tests were two-sided and used a significance level of 0.05. Data handling and analysis were performed with SPSS software for Windows, version 17.0 (SPSS Inc., Chicago, IL).

\section{Results}

A total of 35 consecutive HBsAg-positive, HBeAg-negative, and genotype D treatment-naive patients were enrolled. The mean age was $38.7 \pm 11.5$ years with a male to female ratio of 33:2. All the patients were able to complete 48 weeks of PEG-IFN $\alpha$-2a treatment and 24 weeks posttreatment follow-up. One patient required treatment discontinuation due to thrombocytopenia for 2 weeks but later completed 48 weeks of treatment with reduced dose of PEG-IFN $\alpha-2 \mathrm{a}$. Of the total patients, nine (25\%) required reduction of PEG-IFN dose, the main reasons being neutropenia in six $(17.1 \%)$ patients, thrombocytopenia in two $(5.7 \%)$, and flu-like syndrome in one $(2.9 \%)$. Two out of the six patients who developed neutropenia received additional G-CSF support and continued to receive PEGIFN. One patient developed a mild skin rash which disappeared after discontinuation of PEG-IFN therapy at week 48. None of our patients had significant psychiatric illness.

Overall, EVR, ETVR, and SVR were seen in $8.6 \%$ (3/35), 25.7\% (9/35), and 22.9\% (8/35) patients, respectively. When analyzed on the basis of a cutoff level of $<20,000$ copies $\mathrm{ml}^{-1}$, EVR, ETVR, and SVR were seen in
$42.9 \%$ (15/35), $48.6 \%$ (17/35), and 57.1\% (20/35) patients, respectively (Fig. 1). Only one patient had relapse after achieving ETVR.

In univariate analysis, among all baseline characteristics (Table 1) only pretreatment of weight, triglycerides, HBV DNA and ALT levels were the predictors of SVR. Baseline median ALT level was significantly higher at 94 (67-195) $\mathrm{U}^{-1}$ in patients who achieved SVR, as compared with nonresponders who had median ALT level of 71 (43-84) $\mathrm{U}^{-1}(p=0.034)$. Baseline HBV DNA level in patients who achieved SVR was lower at 5.8 (5.5-6.8) $\log _{10}$ copies $\mathrm{ml}^{-1}$, whereas in nonresponders it was significantly higher at $7.8(6.6-7.8) \log _{10}$ copies $\mathrm{ml}^{-1}(p=0.004)$. The mean age of patients who attained SVR was $36.5 \pm 10.5$ years as compared with $41.8 \pm 12.5$ years in nonresponders $(p=0.214)$. The mean $\log _{10} \mathrm{HBsAg}$ pretreatment level among patients who obtained SVR was $4.01 \pm 0.07$ $\mathrm{IU} \mathrm{ml} \mathrm{m}^{-1}$, whereas in nonresponders it was $4.13 \pm 0.50 \log _{10}$ $\mathrm{IU} \mathrm{ml} \mathrm{m}^{-1}$ ( $p=0.483$ ) (Fig. 2). In responders, the mean HBsAg level reduced to $3.14 \pm 0.61 \log _{10} \mathrm{IU} \mathrm{ml}^{-1}$ at 48 weeks (end of treatment), whereas in nonresponders it remained similar at $3.95 \pm 0.57 \log _{10} \mathrm{IU} \mathrm{ml}^{-1}(p=0.001)$. At the end of follow-up, the mean HBsAg level in patients who achieved SVR was $2.31 \pm 1.00 \log _{10} \mathrm{IU} \mathrm{ml}^{-1}$ and in nonresponders it was $3.82 \pm 0.55 \log _{10} \mathrm{IU} \mathrm{ml}^{-1}(p=$ 0.001). At baseline, HBsAg levels did not correlate well as shown in the scatter plot with best-fit line in Fig. 3a ( $r=0.040, p=0.778)$. However, serum HBV DNA had significant correlation with HBsAg levels at the end of treatment ( $r=0.701, p=0.001$ ) and at the end of follow-up ( $r=0.701, p=0.001$ ) as depicted in Fig. 3b and c.

The liver biopsies of 33 (94\%) patients had grade A1 or A2 changes and 29 (83\%) had stage F1 or F2 changes,
Fig. 1 PEG-IFN response shown at HBV DNA $<20,000$ copies $\mathrm{ml}^{-1}$ and HBV DNA $<400$ copies $\mathrm{ml}^{-1}$ at EVR, ETVR, and SVR

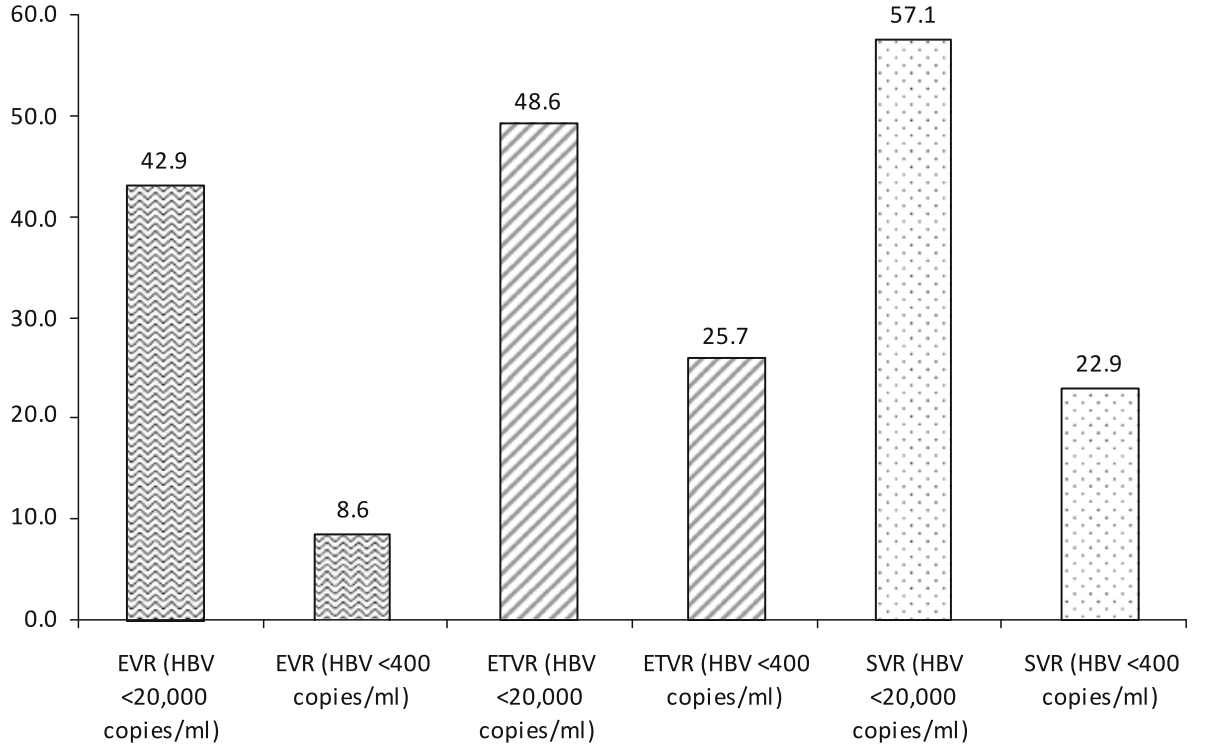


Fig. 2 HBsAg levels and their relationships with baseline, end of treatment, and end of followup HBV (DNA) levels

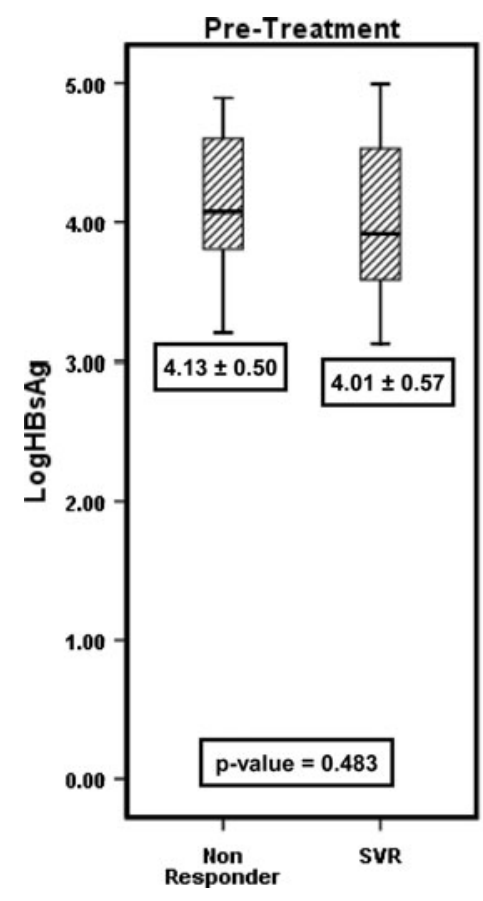

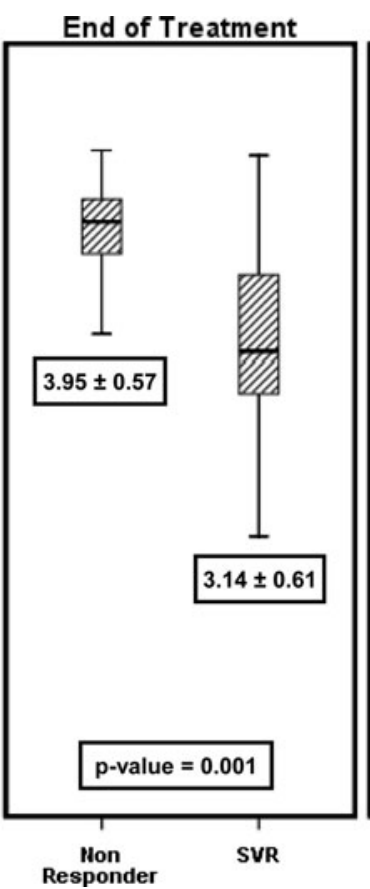

End of Follow-up

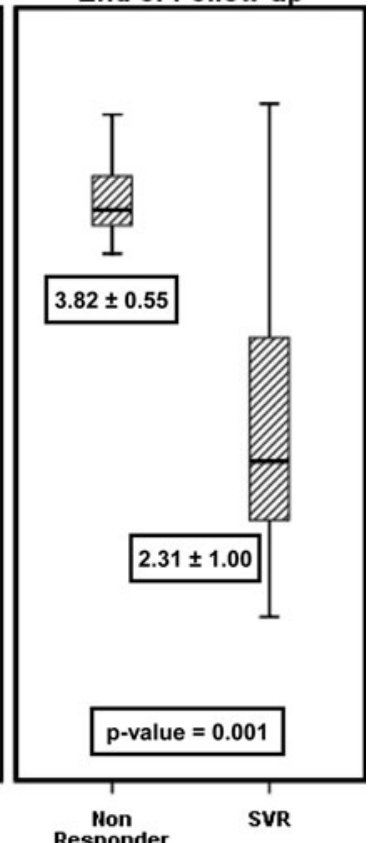

which suggested that the majority of patients had early stages of the disease. The differences in histological staging $(p=0.489)$ and grading $(p=0.660)$ in responders and nonresponders were not statistically significant. Mild steatosis was seen in $19(54.2 \%)$ patients, moderate in 7 (18.9\%), severe in $2(5.7 \%)$, whereas 7 patients $(18.9 \%)$ did not show any significant steatosis. The levels of steatosis in responders and nonresponders were not statistically significant as a predictor of response $(p=0.717)$.

On multivariate logistic regression analysis, weight [odds ratio (OR) 0.89 , 95\% confidence interval (CI) 0.81-0.98, $p=0.048$ ], serum ALT (OR 1.01, 95\% CI $1.00-1.03, p=0.046), \log _{10}$ HBV DNA (OR 0.15, 95\% CI $0.03-0.70, p=0.016$ ), and triglycerides (OR 0.06, 95\% CI $0.006-0.59, p=0.016)$ were identified as independent predictors of SVR (Table 2).

\section{Discussion}

This is the first prospective study that describes the efficacy of PEG-IFN $\alpha$-2a in HBeAg-negative CHB genotype D-naive patients from the Middle East and provides a detailed analysis of baseline and on treatment predictors of response. It has been shown that response to IFN-based therapy is HBV genotype dependent, being associated with both qualitative as well as quantitative responses. The present study of CHB genotype D patients showed a higher SVR of $57.1 \%$ than previously reported, as based on the earlier, less stringent definition of SVR (HBV DNA $<20,000$ copies $\mathrm{ml}^{-1}$ ). Erhardt et al. [10] reported that
HBV genotype A is associated with a significantly higher SVR to IFN than HBV genotype D and showed better SVR rates than genotype $\mathrm{C}, \mathrm{B}$, or $\mathrm{E}$. They also reported SVR to IFN was 59 versus $29 \%$ in HBeAg-negative genotype A compared with genotype $\mathrm{D}$, respectively. In the same study, no statistically significant difference was reported in SVR between $\mathrm{HBeAg}$-positive and -negative patients [37 vs. $40 \%=$ nonsignificant $(\mathrm{NS})]$. In a recent pooled analysis [11] of more than 1,200 patients treated with either standard alpha interferon or PEG-IFN, the rate of SVR for HBeAg-negative patients was $34 \%$ for genotype A, 32\% for genotype B, $50 \%$ for genotype C, and $21 \%$ for genotype D. Similarly, earlier studies with standard alpha IFN found that patients with genotype $\mathrm{A}$ had better response rates than patients with genotypes B, C, or D [12]. Low sustained response rates of even $<10 \%$ have also been reported for HBeAg-negative patients, much lower than HBeAg-positive patients and most of those studies were performed in the Mediterranean area [13-15]. Most of these patients received standard interferon where the response rate was much lower than expected.

Marcellin et al. [16] used PEG-IFN $\alpha-2 \mathrm{a}$ in HBeAgnegative patients and reported an ETVR of $81 \%$ and SVR of $43 \%$ (using HBV DNA $<20,000$ copies $\mathrm{ml}^{-1}$ ), but when the HBV DNA level was reduced to $<400$ copies $\mathrm{ml}^{-1}$, the ETVR rate declined significantly to $63 \%$ and SVR reduced to $19 \%$. When the combined response of ALT normalization and HBV DNA suppression to $<20,000$ copies $\mathrm{ml}^{-1}$ was taken together, the response rate was further reduced to $36 \%$ (included patients had no history of $\mathrm{CHB}$ treatment only within the previous 6 months). However, the 

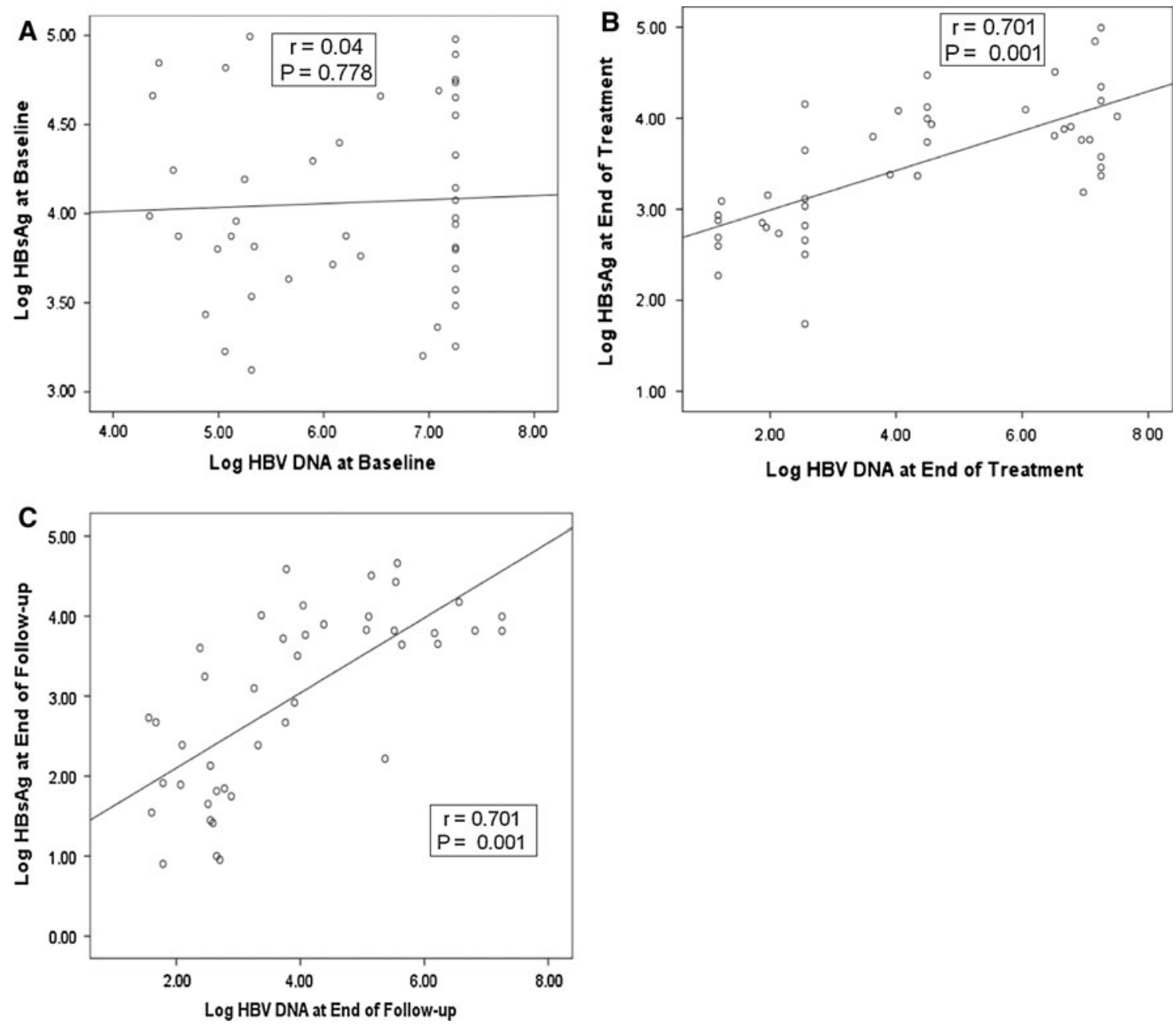

Fig. 3 a Scatter plot showing the best-fit line. No correlation is observed between HBsAg level and HBV DNA level at baseline. b Significant correlation between HBsAg level and HBV DNA at end

of treatment. c Significant correlation between HBsAg level and HBV DNA at end of follow-up

Table 2 Showing multivariate regression analysis

\begin{tabular}{|c|c|c|c|c|}
\hline Characteristic & Responder $(n=20)$ & Nonresponder $(n=15)$ & OR $(95 \% \mathrm{CI})$ & $p$ value \\
\hline Weight (kg) & $77.1(66.0-80.7)$ & $77.0(72.5-86.0)$ & $0.89(0.81-0.98)$ & 0.048 \\
\hline Serum ALT $\left(\mathrm{IU} \mathrm{ml}^{-1}\right)$ & $94.5(67.2-195.5)$ & $71.0(43.0-84.0)$ & $1.01(1.00-1.01)$ & 0.046 \\
\hline Serum HBV DNA (log copies $\mathrm{ml}^{-1}$ ) & $5.8(5.5-6.8)$ & $7.8(6.6-7.8)$ & $0.15(0.03-0.70)$ & 0.016 \\
\hline Triglycerides $\left(\mathrm{mmol} \mathrm{l}^{-1}\right)$ & $0.80(0.64-1.28)$ & $1.85(1.30-2.10)$ & $0.06(0.006-0.59)$ & 0.016 \\
\hline
\end{tabular}

combined response of our cohort was 57\% in genotype D-naive patients. In a later study [17], a better combined response of ALT normalization and HBV DNA suppression was reported (45\%) with PEG-IFN $\alpha-2 \mathrm{a}$ in $\mathrm{HBeAg-}$ negative patients. Flink et al. [18] treated $90 \mathrm{HBeAg-}$ positive naive patients with PEG-IFN $\alpha-2 b$; only $10 \%$ of patients sustained HBV DNA level $<400$ copies $\mathrm{ml}^{-1}$ at the end of follow-up, whereas none of the 30 previously treated patients with IFN, lamivudine, or both attained this level. This showed that the naive patients respond better than previously treated patients, although in our cohort the response rate was better $(22 \%)$ and these naive patients were $\mathrm{HBeAg-negative.} \mathrm{In} \mathrm{another} \mathrm{recently} \mathrm{published} \mathrm{ran-}$ domized controlled PEG-IFN $\alpha-2$ a trial [19] in HBeAgnegative patients (mean age $47 \pm 10$ years), HBV DNA was undetectable in $11 / 30(37 \%)$ patients at week 48 and SVR (HBV DNA $<2,000 \mathrm{IU} \mathrm{ml}^{-1}$ ) at 72 weeks was achieved in $6 / 30(20 \%)$, but patients were not analyzed 
according to genotype. No difference in sustained virological and biochemical response rates was observed between the two treatment regimens (PEG-IFN alone and PEG-IFN plus adefovir dipivoxil). The most likely explanations for slightly higher SVR in the present study are that the patients were of a slightly younger age group (mean age $38.7 \pm 11.5$ years), were treatment naive with no significant drug mutation, and G-CSF was used as needed. In contrast, Buster et al. [20] recommended that PEG-IFN should not be given to HBeAg-positive genotype-D patients, because they had a low chance of SVR (SVR in genotype $A=37, B=25, C=20$, and $D=8 \%$ ) irrespective of ALT and HBV DNA levels. It is worth mentioning that $24 \%$ (38) of SVR patients and $24.4 \%$ (143) of non-SVR patients had a history of previous treatment failure (IFN or lamivudine therapy), whereas our study included treatment-naive patients, which in-turn may have modulated a better virologic response due to reasons mentioned earlier. It is also possible that the liberal use of G-CSF would be able to enhance the response rates, given that six of our patients (17\%) required PEG-IFN dose reductions related to neutropenia.

In our study, a high baseline ALT, low baseline HBV DNA, low triglycerides, and low body weight were identified as pretreatment independent predictors of SVR. Elevated ALT and low HBV DNA [21, 22] levels have previously been reported as baseline predictors of response with PEG-IFN. Although low serum triglycerides and lower body weight have been reported as predictors of SVR in HCV patients treated with PEG-IFN [23], these have not been described in CHB patients. Female sex [24] and younger age [25] have also been reported to be predictors of response in $\mathrm{CHB}$, but age and the sex did not predict a higher response rate in the present study possibly because most of the patients were males (94\%) and almost all were young or middle aged. As such, the newly identified predictors of SVR should be validated in larger genotype-specific studies.

Manesis et al. [26] reported that low pretreatment HBsAg levels were found to be the only significant prognostic predictor of $\mathrm{HBsAg}$ seroconversion after conventional interferon treatment in HBeAg-negative CHB. Previous studies have also revealed that low baseline HBsAg levels were more reliable than serum HBV DNA levels in predicting response to PEG-IFN [27-29]. In the present study, there was no significant difference in the median pretreatment HBsAg level $\left(4.0 \log _{10} \mathrm{IU} \mathrm{ml}^{-1}\right)$ in patients with SVR compared with nonresponders (3.9 $\log _{10}$ $\left.\mathrm{IU} \mathrm{ml}{ }^{-1}, p=0.088\right)$. However, the low baseline HBV DNA levels and high ALT levels correlated well in univariate analysis predicting SVR as demonstrated by others. A recently published study from France [30] had similar findings as ours, wherein their mean pretreatment serum
HBsAg levels were similar in patients who did or did not develop SVR $\left(3.6 \pm 0.8\right.$ vs. $3.6 \pm 0.6 \log _{10} \mathrm{IU} \mathrm{ml}^{-1}$, $p=0.8$ ). In contrast, low pretreatment HBV DNA levels correlated significantly with sustained response. In the present study, serum HBsAg levels were significantly reduced from 4.13 to $3.14 \log _{10} \mathrm{IU} \mathrm{ml}^{-1}$ at 48 weeks and further reduced to $2.13 \log _{10} \mathrm{IU} \mathrm{ml}^{-1}$ at 72 weeks. This is supported by the finding that the reduction of serum HBsAg levels parallels the decline of HBV DNA and intra-hepatic covalently closed circle DNA (cccDNA) [31]. Although the loss of HBsAg is the ultimate goal in the management of $\mathrm{CHB}$, in clinical practice, it is uncommon and accounts for $3-5 \%$ of cases [32, 33] with PEG-IFN therapy. None of our patients showed a loss of HBsAg marker at 72 weeks; probably the total number of patients was small $(n=35)$, and all of them were genotype D which exhibits a lower frequency of HBsAg loss $[34,35]$.

Pretreatment higher necroinflammatory and fibrosis scores have been reported as a predictor of SVR [36], but these factors were not seen in our group of patients, which was likely due to the younger age of our patients and the majority had lower necroinflammatory/fibrosis score [A1 and A2 (94\%), F1 and F2 (83\%)], and thus a significant difference between responders and nonresponders in those with higher necroinflammatory and fibrosis scores could not be demonstrated.

There are few limitations to our study, including no measurement of HBsAg level at 3 months where a significant decrease in HBsAg levels might have predicted the EVR to treatment [5], and the relatively small number of patients.

In conclusion, this study has shown that about a quarter of HBeAg-negative genotype D-naive patients treated with PEG-IFN $\alpha$-2a achieved SVR based on a more stringent definition of SVR (HBV DNA $<400$ copies $\mathrm{ml}^{-1}$ ). The response rate was $>50 \%$ when a cutoff level of HBV DNA $<20,000$ copies $\mathrm{ml}^{-1}$ was adopted. Pretreatment predictors of SVR were low weight, high ALT, low HBV DNA level, and low triglycerides (a newer predictor). Pretreatment HBsAg level does not predict SVR in HBeAg-negative genotype D patients treated with PEG-IFN $\alpha$-2a, although a decline in HBsAg levels correlate with a decline in HBV DNA levels. However, given the expectation of long-term suppression of viremia in such patients, we believe that PEG-IFN treatment could be offered to a select group of patients as identified by the presence of favorable pretreatment predictors of response and larger randomized controlled trials should be conducted in this category of patients from the Middle-Eastern populations.

Acknowledgements The authors want to thank Dr. Abdullah Al Mohaizaie (Clinical Pharmacist), Dr. Hamad Al-Suhaibani 
(Radiologist), and Mr. Naser Elkum (Statistician) for their scientific contribution to accomplish this study.

Conflict of interest Dr. Al-Ashgar, Dr. Bzeizi and Dr. Aljumah are consultants for advice and are on the speaker's bureau of BristolMyers Squibb. Dr. Bzeizi is also consultant, advises and is on the speaker' bureau of Glaxo Smith-Kline. Dr. Sanai is a consultant advises and is on the speaker's bureau of Bristol-Myers Squibb and received grants for some other projects. He is a consultant, advises Scherring-Plough and received grants from Roche and Glaxo SmithKline. Dr. Abdo is a consultant, advises and is on the speaker's bureau of Scherring-Plough, Glaxo Smith-Kline and Bristol-Myers Squibb.

\section{References}

1. Lavanchy D. Hepatitis B virus epidemiology, disease burden, treatment, and current and emerging prevention and control measures. J Viral Hepat 2004;11:97-107

2. Abdo AA, Al-Jarallah BM, Sanai FM, et al. Hepatitis B genotypes: relation to clinical outcome in patients with chronic hepatitis B in Saudi Arabia. World J Gastroenterol 2006;12: 7019-7024

3. Liaw YF, Leung NW, Kao JH, et al. Asian-Pacific consensus statement on the management of chronic hepatitis B: a 2008 update. Hepatol Int 2008;2:263-283

4. Chan HLY, Wong GLH, Wong VWS. A review of the natural history of chronic hepatitis B in the era of transient elastography. Antivir Ther 2009;14:489-499

5. Moucari R, Korevaar A, Lada O, et al. High rates of HBsAg seroconversion in $\mathrm{HBe} \mathrm{Ag}$-positive chronic hepatitis $\mathrm{B}$ patients responding to interferon: a long-term follow-up study. J Hepatol 2009;50:1084-1092

6. Janssen HL, van Zonneveld M, Senturk H, et al. Pegylated interferon alfa- $2 \mathrm{~b}$ alone or in combination with lamivudine for HBeAg-positive chronic hepatitis B: a randomized trial. Lancet. 2005;365(9454):123-129

7. Marcellin P, Bonino F, Lau GK, et al. Sustained response of hepatitis $\mathrm{B}$ e antigen-negative patients 3 years after treatment with peginterferon alpha-2a. Gastroenterology. 2009;136:21692179

8. Gish RG, Lau DT, Schmid P, Perrillo R. A pilot study of extended duration peginterferon alfa-2a for patients with hepatitis B e antigen-negative chronic hepatitis B. Am J Gastroenterol 2007;102(12):2718-2723

9. Wong GL, Chan HL. Predictors of treatment response in chronic hepatitis B. Drugs. 2009;69:2167-2177

10. Erhardt A, Blondin D, Hauck K, et al. Response to interferon alfa in hepatitis B virus genotype dependent: genotype A is more sensitive to interferon than genotype D. Gut. 2005;54:1009-1013

11. Erhardt A, Ludwig AD, Brunetto M, et al. HBV genotypes are the strongest predictors of response to interferon alfa treatment: multivariate evaluation in 1229 hepatitis B patients [abstract]. Hepatology. 2008;48:700A

12. Brunetto MR, Oliveri F, Colombatto $\mathrm{P}$, et al. Treatment of chronic anti-HBe positive hepatitis $B$ with interferon-alpha. J Hepatol 1995;22:42-44

13. Brunetto MR, Giarin M, Saracco G, et al. Hepatitis B virus unable to secrete e antigen and response to interferon in chronic hepatitis B. Gastroenterology. 1993;105:845-850

14. Pastore G, Santantonio T, Milella M, et al. Anti-HBe-positive chronic hepatitis B with HBV-DNA in the serum response to a 6-month course of lymphoblastoid interferon. J Hepatol $1992 ; 14: 221-225$
15. Hadziyannis $S$, Bramou $T$, Makris $A$, et al. Interferon alfa- $2 b$ treatment of $\mathrm{HBeAg}$ negative/serum HBV DNA positive chronic active hepatitis type B. J Hepatol 1990;11(1):S133-S136

16. Marcellin $\mathrm{P}$, Lau GKK, Bonino F, et al. Peginterferon alfa-2a alone, lamivudine alone, and the two in combination in patients with HBeAg-negative chronic hepatitis B. N Engl J Med 2004;351:1206-1217

17. Piratvisuth T, Lau G, Chao YC, et al. Sustained response to peginterferon alfa-2a (40 kD) with or without lamivudine in Asian patients with $\mathrm{HBeAg}$-positive and $\mathrm{HBeAg}$-negative chronic hepatitis B. Hepatol Int 2008;2:102-110

18. Flink HJ, Hansen BE, Heathcote EJ, et al. Successful treatment with peginterferon alfa- $2 b$ of $\mathrm{HBeAg-positive} \mathrm{HBV}$ nonresponders to standard interferon or lamivudine. Am J Gastroenterol 2006;101(11):2523-2529

19. Piccolo P, Lenci I, Demelia L, et al. A randomized controlled trial of pegylated interferon-alpha $2 \mathrm{a}$ plus adefovir dipivoxil for hepatitis B e antigen-negative chronic hepatitis B. Antivir Ther 2009; 14:1165-1174

20. Buster EH, Hansen BE, Lau GK, et al. Factors that predict response of patients with hepatitis B e antigen-positive chronic hepatitis B to peginterferon-alfa. Gastroenterology. 2009;137:2002-2009

21. Lok AS, Wu PC, Lai CL, et al. A controlled trial of interferon with or without prednisone priming for chronic hepatitis B. Gastroenterology. 1992;102:2091-2097

22. Perrillo RP, Schiff ER, Davis GL, et al. A randomized, controlled trial of interferon alfa- $2 b$ alone and after prednisone withdrawal for the treatment of chronic hepatitis B. The Hepatitis Interventional Therapy Group. N Engl J Med 1990;323:295-301

23. Testino G, Sumberaz A, Ancarani AO, et al. Influence of body mass index, cholesterol, triglycerides and steatosis on pegylated interferon alfa-2a and ribavirin treatment for recurrent hepatitis $\mathrm{C}$ in patients transplanted for $\mathrm{HCV}$ and alcoholic cirrhosis. Hepatogastroenterology. 2009;56:501-503

24. Bonino F, Marcellin P, Lau GK, et al. Predicting response to peginterferon alpha-2a, lamivudine and the two combined for HBeAg-negative chronic hepatitis B. Gut. 2007;56:699-705

25. Papatheodoridis GV, Manesis E, Hadziyannis SJ. The long-term outcome of interferon-alpha treated and untreated patients with HBeAg-negative chronic hepatitis B. J Hepatol 2001;34:306-313

26. Manesis EK, Hadziyannis ES, Angelopoulou OP, et al. Prediction of treatment related HBsAg loss in $\mathrm{HBeAg}$-negative chronic hepatitis B: a clue from serum HBsAg levels. Antivir Ther 2007; 12:73-82

27. Brunetto MR, Moriconi F, Bonino F, et al. Hepatitis B virus surface antigen levels: a guide to sustained response to peginterferon alfa-2a in HBeAg-negative chronic hepatitis B. Hepatology. 2009;49:1141-1150

28. Tangkijvanich $\mathrm{P}$, Komolmit $\mathrm{P}$, Mahachai V, Sa-nguanmoo $\mathrm{P}$, Theamboonlers A, Poovorawan Y. Low pretreatment serum $\mathrm{HBsAg}$ level and viral mutations as predictors of response to PEG-interferon alpha-2b therapy in chronic hepatitis B. J Clin Virol 2009;46:117-123

29. Lau GK, Marcellin P, Brunetto M, et al. On-treatment HBsAg decline during peginterferon alfa-2a $(40 \mathrm{KD}) \pm$ lamivudine in patients with $\mathrm{HBeAg}$-positive $\mathrm{CHB}$ as a potential predictor of durable off-treatment response [abstract]. Hepatology. 2008;48: $714 \mathrm{~A}$

30. Moucari R, Mackiewicz V, Lada O, et al. Early serum HBsAg drop: a strong predictor of sustained virological response to pegylated interferon alfa-2a in $\mathrm{HBeAg}$ negative patients. Hepatology. 2009;49:1151-1157

31. Werle-Lapostolle B, Bowden S, Locarnini S, et al. Persistence of cccDNA during the natural history of chronic hepatitis B and decline during adefovir dipivoxil therapy. Gastroenterology. 2004;126:1750-1758 
32. Tangkijvanich $P$, Komolmit $P$, Mahachai V, Sa-Nguanmoo $P$, Theamboonlers A, Poovorawan Y. Comparison between quantitative hepatitis B surface antigen, hepatitis B e-antigen and hepatitis B virus DNA levels for predicting virological response to pegylated interferon-alpha-2b therapy in hepatitis B e-antigenpositive chronic hepatitis B. Hepatol Res 2010;40:269-277

33. EASL. Clinical Practice Guidelines: management of chronic hepatitis B. J Hepatol 2009;50:227-242

34. Buster EH, Flink HJ, Cakaloglu Y, et al. Sustained HBeAg and HBsAg loss after long-term follow-up of $\mathrm{HBeAg}$-positive patients treated with peginterferon alpha-2b. Gastroenterology. 2008;135:459-467

35. Sanchez-Tapias JM, Costa J, Mas A, Brugera M, Rodes J. Influence of hepatitis B virus genotype on the long-term outcome of chronic hepatitis B in western patients. Gastroenterology. 2002;123:1848-1856

36. Wong DK, Cheung AM, O'Rourke K, Naylor CD, Detsky AS, Heathcote J. Effect of alpha-interferon treatment in patients with hepatitis B e antigen-positive chronic hepatitis B. A meta-analysis. Ann Intern Med 1993;119:312-323 